who play an increasing role in the families of children with lifelimiting conditions.

Aim To explore how grandparents experience the death of a grandchild who died from a life-limiting condition.

Methods A purposive sampling technique was used to recruit participants who: (i) identified themselves as fulfilling a grandparenting role; (ii) were bereaved for between six and 24 months; (iii) had a grandchild that died from a life-limiting condition. Grandparents who were the principal carers of the deceased grandchild were excluded.

Semi-structured, individual, face-to-face interviews were conducted in participants own homes. Field notes were taken during and immediately following the interviews.

Findings Seven individuals participated in this study. Findings indicated a number of contextual factors that affect the experience of bereaved grandparents, including intergenerational bonds, identity and perceived changes in role following the death of their grandchild. Bearing witness to the suffering of their child and an inability to 'make things better' were recurrent themes. The essence of grandparents' experiences was interpreted as focusing on fulfilling a parenting role to their child.

Conclusions and implications The research identified that primary motivation of grandparental support stems from their role as a parent, and not as a grandparent.

The breadth of pain experienced by grandparents is complicated by the multigenerational positions they occupy within the family. The transition from before to after death exacerbated the experience of pain. The findings from this study suggest the development of practice to better understand and support grandparents of children with a life-limiting condition during life, in addition to bereavement support.

\section{O-23 WORKPLACE SUPPORT - A BEREAVEMENT TOOLKIT}

${ }^{1}$ Karen Norman, 'Laura Kelly, ${ }^{2}$ Elissa Dennis. ${ }^{1}$ St Catherine's Hospice, Crawley, UK; ${ }^{2}$ Unum Ltd

\subsection{6/bmjspcare-2016-001245.23}

For Dying Matters Awareness week in 2015, the hospice held a workshop for employers across the local area. Attended by a range of large and small employers, it was clear that there were significant differences in the way they manage terminal illness and bereavement as it presents in the workplace.

Recognising a need to equip managers to handle difficult conversations and offer support, we partnered with an employee benefits company to address the need. Keen to reach out to all UK employers with whom they provide solutions, they agreed to jointly develop an online resource aimed specifically at all UK line managers.

The interactive toolkit covers topics including;

- What is bereavement?

- Working through bereavement

- Bereavement in the workplace

- Supporting a bereaved colleague

- Support if a colleague dies.

The toolkit offers information on the effects of grief and bereavement and the impact this may have on employees' work.
It also provides advice on understanding challenges a bereaved colleague will face and dealing with practicalities. With accessible and clear guidance for each topic, the toolkit is designed to help line managers feel in control when managing death and bereavement in their teams.

Both organisations have actively championed the use of the tool via television, radio, newspapers and magazines and have had articles printed and online coverage. Social media has been very active and it is clear that the tool has been a great success.

With around 20\% of our patients being of working age, the importance and impact of the workplace to our work needs to be recognised and we are currently in discussion with the Compassionate Employers Programme about furthering this initiative. Meanwhile, many business leaders have been contacting us via the website, so the potential for this toolkit and the partnership working is exciting.

\section{0-24 RELATIVES AND FRIENDS THROUGH TRAUMA: A SUPPORT GROUP FOR ADULTS BEREAVED BY SUICIDE}

Sarah Popplestone-Helm, Matthew Jackson, Alison Cooper. St Richard's Hospice, Worcester, Great Britain

\subsection{6/bmjspcare-2016-001245.24}

The Hospice Family Support Team, working in partnership with Bereavement Support South Worcestershire, developed and facilitated a bereavement group for adults bereaved by suicide. An increase in referrals for this client group indicated the need for support within this specialist area and the first 'Relatives and Friends Through Trauma Group' was developed.

Suicide is not an area of work that a Hospice would usually be involved with and the prospect felt challenging. However, partnership working with a commissioned bereavement service, hosted by the hospice enabled the team to explore working with bereaved people following sudden and traumatic death, and to build on their existing skills.

The first 'Relatives and Friends through Trauma' (RAFTT) was attended by eight clients, and facilitated by two members of staff and one volunteer. It ran weekly for eight sessions. The objective was to enable individuals to tell their stories, express their grief and to develop a sense of community and support within the group.

Clients were apprehensive, but they shared stories and experiences, and developed a strong and empathic connexion with each other. It was a powerful process to witness. Everyone had the choice to share when they felt able; the compassion, strength, honesty, pain, despair and sadness were palpable.

Support for the team was crucial. De-briefs following each group meeting enabled facilitators to explore how the session had impacted on them. Supervision was also provided on a regular basis.

The group now meets socially. There is potential for them to invite future RAFTT groups to join them, and to develop an independent community support group. They have been filmed talking about their experience of the group in order to encourage others to seek support. Following on from the success of RAFTT, a group for children bereaved by suicide is now under consideration. 